\title{
Review: levonorgestrel and mifepristone are effective emergency methods for preventing pregnancy after unprotected intercourse
}

Cheng L, Gülmezoglu AM, Van Oel CJ, et al. Interventions for emergency contraception. Cochrane Database Syst Rev 2004;(3):CD001324.

\section{Q Which emergency contraceptive methods are the most effective for preventing pregnancy after unprotected intercourse?}

\section{METHODS}

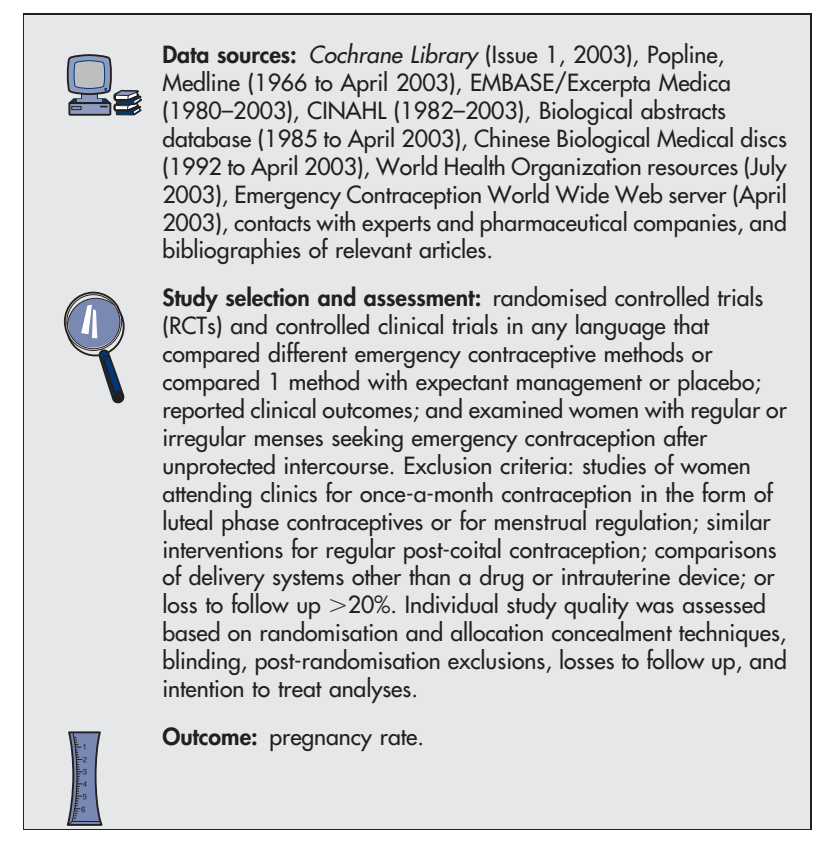

\section{MAIN RESULTS}

48 trials (33 110 women) met the selection criteria. Selected results are reported in the table. Pregnancy rates did not differ for a single dose of levonorgestrel, $1.5 \mathrm{mg}$, and 2 doses of $0.75 \mathrm{mg}$ given 12 hours apart ( 2 trials, $\mathrm{n}=3830$ ); levonorgestrel, $1.5 \mathrm{mg}$, and mifepristone, 25-50 mg ( 8 trials, $\mathrm{n}=2292$ ); levonorgestrel, $1.5 \mathrm{mg}$, and mifepristone, $\leqslant 10 \mathrm{mg}$ ( 7 trials, $\mathrm{n}=6118$ ); mifepristone, $>50 \mathrm{mg}$, and $25-50$ $\mathrm{mg}$ ( 5 trials, $\mathrm{n}=2464$ ); mifepristone, $>50 \mathrm{mg}$, and $\leqslant 10 \mathrm{mg}$ ( 2 trials, $\mathrm{n}=1384$ ); or danazol and the Yuzpe regimen ( 2 trials, $\mathrm{n}=485$ ).

For correspondence: $\mathrm{Dr} \mathrm{L}$ Cheng, International Peace Maternity and Child Health Hospital, China Welfare Institute, Shanghai, China. linanc@online. sh.cn

Source of funding: David and Lucile Packard Foundation, CA, USA.

\section{CONCLUSIONS}

Levonorgestrel (which is as effective when used as a single dose of $1.5 \mathrm{mg}$ or as 2 doses of $0.75 \mathrm{mg}$ taken $12 \mathrm{~h}$ apart) and mifepristone, $25-50 \mathrm{mg}$, are effective emergency methods for preventing pregnancy after unprotected intercourse.

\section{Commentary}

T he review by Cheng et al concludes that levonorgestrel or mifepristone are more effective and better tolerated than the traditionally used Yuzpe method. Mifepristone, however, remains controversial because of its identity as the "abortion" pill. It is also associated with delayed onset of menses. The thorough search of specialised databases, inclusion of studies in any language, consultation with experts, and sound methodological quality of most of the individual studies gives strength to the authors' conclusions. A levonorgestrel regimen of $1.5 \mathrm{mg}$, as a single or divided dose, is the treatment of choice when available, although it may be more costly than the Yuzpe method.

The clinical safety and effectiveness of emergency contraception is well established. The challenge for clinicians is to promote the appropriate use of this underused contraceptive option. Few women report having ever used emergency contraception. ${ }^{12}$ It is likely that wider use could prevent many unwanted pregnancies and prevent abortions. Some countries are initiating changes that will make emergency contraception available through pharmacists without prescription. Over-the-counter sales will dramatically increase access and should be supported by healthcare professionals. Clinicians might also consider providing women or couples with an advance dose of emergency contraception for use after unprotected intercourse. Although this approach is controversial, adolescents provided with an advance dose do not have more unprotected sex and actually increase their use of condoms or oral contraceptives. ${ }^{3}$

The take home message is that emergency contraception is safe and effective, and access to this important contraceptive option should be expanded.

Scott Gibson, RN-EC, BScN Niagara-Health System, Niagara-on-the-Lake Site Niagara-on-the-Lake, Ontario, Canada

1 Kaiser Foundation. Women's health care providers' experiences with emergency contraception. June 2003. http://www.kff.org/womenshealth/ 3343-index.cfm. (accessed 19 October 2004).

2 Babaee G, Jamali B, Ali MM. J Sex Marital Ther 2003;29:269-75.

3 McLean R. Perspect Sex Reprod Health 2004;36:134.

Pregnancy rates for various emergency contraceptive methods after unprotected intercourse*

\begin{tabular}{|c|c|c|c|c|}
\hline Comparisons & Number of trials $(\mathrm{n})$ & Weighted event rates & $\operatorname{RRR}(95 \% \mathrm{Cl})$ & NNT (Cl) \\
\hline $\begin{array}{l}\text { Intrauterine device } v \text { expectant } \\
\text { management }\end{array}$ & $1(300)$ & $2 \% \vee 22 \%$ & $91 \%$ (74 to 97 ) & $5(4$ to 9$)$ \\
\hline Levonorgestrel $v$ the Yuzpe regimen & 2 (2789) & $1.3 \%$ v $3.3 \%$ & $49 \%(17$ to 69$)$ & $50(34$ to $\infty)$ \\
\hline Mifepristone $v$ the Yuzpe regimen & $3(2144)$ & $0.45 \%$ v $2.5 \%$ & $86 \%(59$ to 95$)$ & $50(34$ to 100$)$ \\
\hline Mifepristone, $25-50 \mathrm{mg} \mathrm{v} \leqslant 10 \mathrm{mg}$ & $10(8762)$ & $0.73 \% \vee 1.7 \%$ & $38 \%(12$ to 57$)$ & $100(100$ to $\infty)$ \\
\hline Mifepristone $v$ anordrin & $3(439)$ & $0.09 \%$ v $4.1 \%$ & $80 \%$ (8 to 96$)$ & 25 (15 to 100$)$ \\
\hline Mifepristone $v$ danazol & $2(629)$ & $0.47 \%$ v $4.5 \%$ & $90 \%$ (45 to 98$)$ & 25 (15 to 50$)$ \\
\hline
\end{tabular}

*Abbreviations defined in glossary; weighted event rates, RRR, NNT, and Cl calculated from data in article using a fixed effects model. 